\title{
Unlocking the Relationship Between Corporate Entrepreneurship and Firm Performance
}

Authors: Fis, M. A. ${ }^{1}$ and Cetindamar, D. ${ }^{2 *}$

${ }^{1}$ Faculty of Business, Ozyegin University, Istanbul, Turkey, murat.fis@ ozyegin.edu.tr ${ }^{2}$ Faculty of Engineering and IT, University of Technology Sydney, Sydney, Australia, dilek.ck@uts.edu.au

* Corresponding Author.

This paper explores the relationship between corporate entrepreneurship and performance by developing a comprehensive theoretical model based on Schumpeterian understanding of entrepreneurship supported with the Theory of Planned Behavior from social psychology. The model shows how organizational culture (value) triggers a chain effect through its influence on entrepreneurial orientation (attitude) and managerial support (intentions) that ultimately generate impact on corporate entrepreneurship (behavior). We test our model in an emerging economy context and present our results with implications to theory and practice.

Keywords: corporate entrepreneurship, entrepreneurial orientation, organizational culture, performance, managerial support, emerging economy

\section{Introduction}

Transmuting an organization into an "entrepreneurial" one is an eminent, worthwhile strategy in a competitive environment (Shepherd, Patzelt, and Haynie 2010; Stambaugh, Martinez, Lumpkin, and Kataria 2017). Yet, the complexity of the topic still attracts researcher's attention searching for a robust understanding of this firm-level, corporate entrepreneurship (CE) phenomenon (Wales 2015). Since the pioneering work of Peterson and Berger (1971), pointing out the intricacy of the relationship, many studies have tested different internal and external factors to the firm, mediating and/or moderating the relationship between CE and performance (Baker, and Sinkula 2009; Moreno, and Casillas 2008; Wiklund, and Shepherd 2003). However, the literature 
fails to offer solid findings related to the firm performance and the role of CE (Dess, Ireland, Zahra, Floyd, Janney, and Lane 2003).

In this paper, the goal is to shed light on the relationship between $\mathrm{CE}$ and performance through a disparate perspective. The base of our refined model is the Schumpeterian interpretation of entrepreneurship: considering nothing as more important than the behavior itself (Schumpeter 1934). On top of this profound assent, we borrow the "value-attitude-behavior cognitive hierarchy model" from social psychology (Fishbein, and Ajzen 1975) to help us in distinguishing and distilling the roles of different concepts to clarify and solidify the complex relationship between CE and performance. Our proposed model contributes to theory by tackling the two oversights. First, following the call of Covin and Wales (2019) that entrepreneurial orientation (EO) is an incomplete assessment of firm-level entrepreneurship and it needs to be complemented with CE assessments, this paper treats CE as a behavioral construct independent of EO. Second, this paper brings forward the neglected role of organizational culture $(\mathrm{OC})$ into the scene. Distilling the roles of the constructs, and inclusion of the OC helps to re-identify the role of managerial support in this relationship as well.

While not a central focus of the study, the paper also enriches empirical studies through three minor offerings. First, though largely credited and cited, this study will be one of the few empirical studies (Rauch, Wiklund, Lumpkin, and Frese 2009) where EO is measured in five dimensions as suggested by Lumpkin and Dess (1996). Second, majority of studies consider financial outcomes of CE (Moreno, and Casillas 2008) while this study joins to a relatively less empirical works exploring the performance of $\mathrm{CE}$ by taking into the non-financial part of performance into consideration (Zahra, Randerson, \& Fayolle, 2013). Third, the study empirically test the model in the context of an emerging economy with less experience about entrepreneurship (Zahra, Ireland, Gutierrez, and Hitt 2000), has a different cultural background than the frequently researched western economies 
(Bruton, Ahlstrom, and Obloj 2008), and is neglected in literature (Wales, Gupta, and Mousa 2013). The paper tests the proposed model using data collected from 347 Turkish companies.

\section{Theoretical Framework and Hypotheses Development}

As Schumpeter (1934) puts it, an organization will be entrepreneurial only if it fulfills the "function" not when it has non-behavioral firm-level attributes. To Schumpeter (1934), even the number of successful patent applications filed during each year, which definitely is more than a disposition, may not be an appropriate measure for CE. Since patents do not necessarily turn into a commercialized output, even they, cannot yet be an example of entrepreneurship. Actually, being an entrepreneur is "rolling up the sleeves" and turning ideas into profitable realities (Pinchot, 1985). While we develop a model to understand the relationship between CE and performance, we want to benefit from the "value-attitude-behavior cognitive hierarchy model" for illustrative purposes. This model offers a set of concepts related to human behavior that may help to analyse various phenomena, including entrepreneurship (Fishbein, and Ajzen 1975). We expect better distinguished and clarified roles of different variables by the adoption of the model into our case, will bring a breath fresh air to the efforts of solidifying firm level entrepreneurship phenomenon. Moreover the distinctive formulization and refinement will provide richer and more robust contribution to the literature (Zahra, Randerson, and Fayolle 2013).

Proposed model shown in Figure 1, includes environmental and organizational variables and embodies both direct and indirect effects. The model includes the organizational culture (OC) as the "values" part of the hierarchy. OC is the greatly understudied and often neglected factor in CE literature (Covin, and Slevin 1991; Fayolle, Basso, and Bouchard 2010). The model considers that OC and environment impel the formation of the "attitude", EO, in the minds of top management. Concurring with the discrepancy among EO and CE, this paper handles EO as an "attitude" playing an antecedent role rather than an equivalent of CE (Randerson 2016; Zahra, Randerson, and Fayolle 2013). Then, this attitude produces and/or triggers "intentions" reflected through mediating 
managerial support mechanisms and eventually leads to the formation of desired "behavior". Finally, we treat CE as an "activity/behavior" that turns out to be a complex outcome of aspirations, attitudes and/or intentions.

\section{Insert Figure 1 About Here}

This is not only in line with the Schumpeterian paradigm that considers the core of entrepreneurship as the behavior itself (Schumpeter 1934) but resonates with the "aspirations, attitudes, and activity" conceptualization used in Global Entrepreneurship Monitor (GEM) Reports since 2008.

\section{Values: The Internal Building Block - Organizational Culture}

The extension of the art of "recombination" to the moral, cultural, and social organizational spheres, as pointed out by Schumpeter (1934), forms one of the two major thrusts of this study: Considering that OC manifests itself in various features of organizational life (Detert, Schroeder, and Mauriel 2000), it deserves to be a fundamental building block of CE, constituting the "value" part of the hierarchical chain. As widely accepted in social psychology, 'within a given situation, the influence should theoretically flow from abstract values to midrange attitudes to specific behaviors' (Homer, and Kahle 1988: 638). Accordingly, beliefs serve as the informational base driving attitudes, intentions, and behaviors in a consecutive order (Fishbein and Ajzen, 1975). Comparably, we propose that the OC, the basic internal context (Kreiser, Marino, Dickson, and Weaver 2010) of the firm, together with the external context, i.e. environmental factors is expected to perform the role of "beliefs/aspirations" and confluence the formation of attitude, namely EO.

Past research shows the key role of internal mechanisms in triggering CE (Hornsby, Kuratko, and Montagno 1999). Besides formal ones, there are many informal internal mechanisms, which may influence CE. Thus, CE is a complex and multidimensional culmination of the interaction of some indeterminate factors (Lumpkin, and Dess 1996; Wiklund, and Shepherd 2005; Zahra 1991). 
Culture at all levels is definitely one of the main phenomena hosting and triggering the indeterminate, internal, informal interactions that shape the entrepreneurial behavior.

OC consists of shared -through generations of employees- philosophies, ideologies, values, assumptions, beliefs, attitudes, norms, and expectations (Kilmann, Saxton, and Serpa 1985). Hence, it serves as the "glue" (Schneider 1988) binding an organization together. As a historically unique, causally ambiguous, and socially complex structure, OC constitutes an ideal example of a valuable, rare, unique, and imperfectly imitable resource set that resource based view defines for sustainable competitive advantage (Barney 1986; Zahra, Hayton, and Salvato 2004). Thus, cultural values play an essential role in shaping the managerial stance and appropriate organizational responses (Schein 1992), besides strategy formulation process (Schneider 1989). Yet, there are very few studies -five to be exact- published at first-rank peer reviewed journals (Fayolle, Basso, and Bouchard 2010), which have empirically examined the role of OC on a firm's ability to develop, maintain, and/or enhance CE (Kreiser, Marino, and Weawer 2002; Wales, Monsen, and McKelvie 2011).

The cultural values of the broader society in which an organization operates may have fundamental impacts on an organization's culture (Hofstede, Neuijen, Ohayv, and Sanders 1990), making it possible to explore these so-called societal dimensions at the organizational level (Earley 1993; Earley and Gibson 1998, Hofstede, Neuijen, Ohayv, and Sanders 1990; Robert, and Wasti 2002; Yilmaz, Alpkan, and Ergun 2005). We do the same and utilize Hofstede's societal dimensions of culture. Yet, our study comprises two societal dimensions, namely individualismcollectivism and power distance as suggested in past studies as major ones studied in various research in various contexts (Engelen, Flatten, Thalmann, and Brettel 2014).

In collectivistic cultures, the priority is on collective goals and cooperative action as opposed to personal interests and maximizing individuals' goals in individualistic cultures (Earley 1989). In terms of organizational collectivism, joint contributions to organizational accomplishments, knowledge sharing, cooperation and collaboration are examples of explicitly rewarded behaviors. In individualistic OCs on the other hand, self-reliance, non-conformity and competition come forward 
and individual decision-making is preferred over group consensus (Triandis, Bontempo, Villareal, Asai, and Lucca 1988). An individualistic culture facilitates the recognition of radical innovation by individual entrepreneurs and seems to be more effective in the case of independent and informal entrepreneurship and/or CE (Shane 1992; Shane 1993). However, it is the group cultural orientation that encourages formal CE behavior (Herbig 1994; Brettel et al., 2015) due to higher collaboration, integration, and knowledge exchange expected. However, free riders, social loafing, and mixed motive behavior are the complicating factors behind collective action (Shane, 1992; 1993).

To date, five studies (e.g. Brettel, Chomik, and Flatten 2015; Cherchem 2017; Engelen, Flatten, Thalmann, and Brettel 2014; Morris, Davis, and Allen 1994; Zahra, Hayton, and Salvato 2004) have empirically investigated OC in firm-level entrepreneurship literature. Among these, studies where researchers utilize "Competing Values Framework", Brettel et al. (2015) finds a significant positive impact of "group" culture -more or less overlapping with collectivism in our case- on all three classical EO dimensions in their study. The study of Engelen et al. (2014) does not find any significant relationship between clan culture that supposedly overlaps by and large with collectivistic culture, and EO, whereas the study of Cherchem (2017) finds a significant relationship in family firms. In the two other remaining studies where researchers use the societal individualism dimension as we do, Morris et al. (1994) and Zahra et al. (2004) find an inverted Ushaped relationship between individualism-collectivism and firm-level entrepreneurship. The inverted U-shaped relationship found in the previous these studies between individualismcollectivism and entrepreneurship, is quite understandable. A "balanced" level of collectivism and individualism leads to greater entrepreneurship. However, individualism and collectivism are polythetic constructs and they may differ according to their relative emphasis on horizontal and vertical social relationships (Triandis \& Gelfand, 1998). Therefore, with the potential high moderating effect of the high power distant cultural structure of the Turkish Society in general, combined with the existence of a strong national cultural dimension like paternalism (Aycan 2001) whereby people in authority assume the role of a "parent", we expect to find a negative relationship 
with high levels of organizational collectivism and EO in our study. Consequently, combining above summarized theoretical and empirical findings, and advantages and disadvantages both individualism and collectivism offer, in the Turkish context, we hypothesize that:

HIa: High level of organizational collectivism is negatively related to EO.

Power distance, which relates to the power distribution in an institution, is another well studied and accepted but neglected dimension. A high degree of power distance in an organization is expected to lead to higher levels of subordinate submissiveness, less participation in decision making, and more resistance to change in the distribution of power (Hofstede 1980). Therefore, increased bureaucracy, more centralized authority, more formal and vertical communication patterns, and organizational structures are possible outcomes of high power distance cultures (Shane 1992; Shane 1993; Yilmaz, Alpkan, and Ergun 2005). Vertical and formal communication patterns and organizational structures inhibit both the diffusion and the acquisition of knowledge through exploration (Shane 1993; Slater, and Narver 1995; Yilmaz, Alpkan, and Ergun 2005). By hindering the flexibility necessary for innovation, bureaucracy prevents creativity and inventiveness (Sathe 1988). Finally, the social changes and entrepreneurship often cause those at the top of the hierarchy to fall and consequently hierarchical cultures seek to minimize change (Shane 1992; Shane 1993). Conformingly, all three previously mentioned studies (Brettel, Chomik, and Flatten 2015; Cherchem 2017; Engelen, Flatten, Thalmann, and Brettel 2014) have studied hierarchical culture of "Competing Values Framework" that more or less overlaps with high power distance cultures in our case have found a negative relationship with EO. In parallel, we propose that:

H1b: High level of organizational power distance is negatively related to EO.

\section{The Attitude: Entrepreneurial Orientation}


Conceptualized as the strategic disposition of top managers toward entrepreneurial behavior (Miller, and Friesen 1982), EO is basically a firm level phenomenon placing firms along a conceptual continuum, which goes from highly conservative to highly entrepreneurial (Covin, and Slevin 1991). Miller (1983), the inventor of the concept, proposes three key dimensions: innovativeness, proactiveness and risk-taking. While innovativeness shows the orientation towards product/service innovations, proactiveness reflects the disposition in pursuing market opportunities and in shaping the environment by being among the very first in the industry. Finally, risk-taking refers the tendency to support innovative projects even when the payoff from such activities is uncertain. Later, Lumpkin and Dess (1996) adds two more dimensions to the construct: 1) competitive aggressiveness, exemplified by an intense disposition to outperform industry rivals, and 2) autonomy, referring to the freedom conveyed to the employees to be self-directed, exercise creativity, pursue opportunities, and champion new ideas.

The phenomenon of EO has been such popular among academicians that the articles on the topic has exceeded that of the main topic of CE (Covin, and Lumpkin 2011; Stambaugh, Martinez, Lumpkin, and Kataria 2017; Wales 2015). Literature has used many labels to tag EO, including mode (Mintzberg 1973); style (Khandwalla 1976); posture (Covin, and Slevin 1989); disposition (Stambaugh, Martinez, Lumpkin, and Kataria 2017) intention; propensity; willingness; tendency (Lumpkin, and Dess 1996); mind-set (Rauch, Wiklund, Frese, and Lumpkin 2004); state of mind (Fayolle, Basso, and Bouchard 2010). Yet, whatever the label has been, what is meant, referred, and measured by EO is definitely not exactly the behavior but "disposition" (Zahra, Randerson, and Fayolle 2013). The study of Stambaugh et al. (2017) finds a strong relationship between subjectively-measured EO risk taking and objectively-measured realized bank risk-taking in their research and finds no significant direct relationship with the other EO dimensions, namely innovativeness, proactiveness, and competitive aggressiveness, and actual entrepreneurial behavior. As nicely put by Fishbein and Ajzen (1975) "when dealing with attitudes, we are concerned with predispositions to behave rather than with the behavior itself. Thus, attitude is viewed as a 
predisposition that does not predispose the person to perform any specific behavior. Rather, it leads to a set of intentions related to behavior." Correspondingly, treating EO as an attitude towards CE and putting intentions in between may help us solidify the "problematic" relationship.

As concisely stated by Atuahene-Gima and Ko (2001: 55): “Organizational orientations are social learning and selection mechanisms that aim to maintain a coherence between management's strategic intent and operational activities." Hence, entrepreneurial orientation should be treated as an important and strategic antecedent variable of corporate entrepreneurship behavior. EO is organizations' readiness or mode, top management's strategic inclination or propensity to initiate and/or conduct CE activities. All in all, It should not be fair to expect behavior without appropriate orientation towards that behavior. In other words, forming the attitude component of the model and with the support mechanisms it may trigger, EO, directly and indirectly serves as a key antecedent of CE behavior.

In line with all these arguments and similar concepts in the other fields of management where the strategic orientation (marketing, alliance, learning) precedes the behavior and final performance (Kandemir, Yaprak, and Cavusgil 2006; Slater, and Narver 1995), and almost all past research treating EO as equivalent of CE (Rauch, Wiklund, Lumpkin, and Frese 2009), we propose that:

H2: A firm's EO has a positive direct impact on all forms of CE: innovation, strategic renewal, and venturing.

\section{Intentions: Managerial Support Mediation}

Fishbein and Ajzen's work (1975) asserts that "the performance or non-performance of a specific behavior is determined by the person's intention to perform that behavior." This formulization raises the question of what may be a concrete form of attitude, transformed into behavior. In fact, managerial support, which can take many concrete forms from providing necessary resources such as time and expertise, to championing innovative ideas, and from 
tolerance for failure to appropriate use of rewards, may offer some examples of attitudes transformed into intentions. In the end, the extent to which a disposition (EO) in the minds of top management that is shaped with values (culture and environment) will be successful in creating desirable outcomes, depends mainly upon the actual support mechanism and resources (intentions) offered towards reaching that goal. Thus, this paper treats managerial support mechanisms as a mediating variable between EO and entrepreneurial behavior. This not only completes the relationship in line with the "value-attitude-behavior cognitive hierarchy model" but also responds to calls made for more tests of mediating variables (Lumpkin, and Dess 1996; Rauch, Wiklund, Lumpkin, and Frese 2009; Wales, Gupta, and Mousa 2013). Consequently, a strategic posture towards entrepreneurship that is embodied in EO as an attitude, leads to some concrete forms of support mechanisms, intentions, that will in turn mediate and facilitate the occurrence of $\mathrm{CE}$ behavior.

As concisely stated by Barringer and Bluedorn (1999:421) “a firm's ability to increase its entrepreneurial behavior is largely determined by the compatibility of its management practices with its entrepreneurial ambitions." In other words, the creation of support mechanisms mostly at the discretion of top management, demands a strategic posture toward entrepreneurship as well. Managerial support refers to all the mechanisms that are at the discretion of managers (Zahra, Ireland, Gutierrez, and Hitt 2000). Senior executives' support plays crucial role in mobilizing internal factors for CE. Hornsby et al.'s (2009) study shows the strong positive relationship between mobilization of resources and middle and above level managers. Therefore, we hypothesize that:

H3: As a disposition toward being more entrepreneurial, higher EO is positively related to managerial support mechanisms, i.e. intentions between the attitude and the behavior.

H4: As a mediating mechanism between attitude and behavior, managerial support mechanisms, i.e. disposition transformed into some concrete forms of support are positively related to all forms of $C E$. 
Moreover, it is likely to observe a direct link between OC and managerial support as well. As a higher order variable with ties to the history of the organization, $\mathrm{OC}$ that characterizes an organization (Cameron and Quinn 2006) may or should have a role in shaping managers' appropriate organizational responses (Schein 1992) or at least constitute the appropriate platform for those mechanisms to cultivate. Based on the literature we expect this support to be much higher in cultures that are more collectivistic and less power distant.

In collectivistic cultures, where the priority is on collective goals and cooperative action as opposed to personal interests and maximizing individuals' goals in individualistic cultures (Earley 1989), group cultural orientation is expected to encourage formal CE behavior (Herbig 1994; Brettel et al., 2015) due to higher collaboration, integration, and knowledge exchange higher levels of social networks (Kim \& Lee, 2006) expected. In individualistic cultures, where priority is on self-reliance, personal interests and maximizing individuals' goals; non-conformity and competition come forward and individual decision-making is preferred over group consensus; just and individualized reward distribution is preferred (Earley 1989, Earley and Gibson 1998, Triandis et al. 1988). Thus, it is quite normal to expect from managers to comply with the existing culture and provide individualized supports instead of a collective one, in highly individualistic cultures. Conformingly:

H5a: High level of organizational collectivism is expected to relate positively to managerial support.

As stressed early in the manuscript, high power distance cultures reflected as relatively more bureaucracy, centralized authority, formal and vertical communication patterns, and organizational structures, regulations, and standard operating procedures (Cameron and Quinn 2006, Shane 1992; Shane 1993; Yilmaz, Alpkan, and Ergun 2005), are expected to facilitate the adoption and 
implementation of more routine and efficiency emphasized projects rather than non-routine relatively more radical intrapreneurial activities this research is about. Moreover, the self-affecting consequences of changes stimulated by firm level entrepreneurial activities especially for those at the top of the hierarchy discourage them to stimulate change (Shane 1992; Shane 1993), thus deploy managerial support. Conformingly:

H5b: High level of organizational power distance is expected to relate negatively with managerial support.

\section{The Dance ${ }^{1}$ Itself: Behavior - CE}

$\mathrm{CE}$ is the sum of an organization's all innovation, renewal and venturing efforts (Guth, and Ginsberg 1990; Zahra 1996). Resulting in a new business within or outside the existing organization, venturing may be the most striking form of these new combinations (Stopford, and Baden-Fuller 1994). Diffusion of an entrepreneurial mood and outlook into entire organizational operations that is a renewal struggle from inside is another manifestation of $\mathrm{CE}$ behavior (Burgelman 1983). This so called strategic renewal function may take place as redefinition of the business concept, reorganization, the introduction of system-wide changes for innovation, and the new strategic direction (Stopford, and Baden-Fuller 1994; Zahra 1993). Finally, referring to the introduction of a new product, process, technology, system, technique, resource, or capability to the firm or its markets, innovation, forms the vital constituent of CE (Sharma, and Chrisman 1999).

Schumpeter's (1934) focus on the entrepreneurial function itself forms the other major thrust of this study. In other words, nothing (who, when, how, how long, for what) is more important than bringing out the new combination, the overt behavior itself. Yet, explaining behavior has been a difficult task and even though "general dispositions tend to be poor predictors of behavior", studies seem to use dispositions to predict and explain behavior (Ajzen 1991). Likewise, research about CE

\footnotetext{
1 Ascribed to the long-lasting discussion (Gartner, 1988; Sarason, Dillard, \& Dean, 2008) in the entrepreneurship literature inspired by the imagery borrowed from W. B. Yeats's 1956 poem.
} 
implicitly assumes that a firm performs -or should perform- entrepreneurial behavior, if it has the orientation/disposition. EO, basically demonstrating a posture towards the desired behavior, is treated as an equivalent of CE behavior in more than 100 studies (Rauch, Wiklund, Lumpkin, and Frese 2009) and is used to assess disposition toward entrepreneurial activity rather than actual involvement in it (Zahra 1991).

As stated previously, this is quite understandable as 'a proximal measure of intention should correlate perfectly with the measure of behavior' (Sutton 1998). Yet, though CE has been shown to make a positive difference in firm performance in various studies, there has been a lack of systematic empirical evidence (Rauch, Wiklund, Lumpkin, and Frese 2009). As argued by Wiklund (1998), EO's "softer characteristics" reflecting the mental orientation that are "not necessarily converted (and may never be) into action", may be one of the primary reasons behind the systematic evidence.

The study of Fishbein and Ajzen (1975) offer a clarification, and distinguish between beliefs, attitudes, intentions, and behaviors. We believe the resulting "value-attitude-behavior cognitive hierarchy model" is quite applicable to our case in fulfilling the gaps and may provide an explanation for the inconsistent findings. With our distinctive formulization and refined model, in which every variable is in its proper place, we expect a much more clear and solid picture of the relationship between CE and firm performance. As Sackmann (1992) points out, "given that organizations are purposive, the manifestations of ideas in practices are important." Thus, we hypothesize:

H6: Different forms of CE are positively related to growth, profitability, and non-financial performance.

\section{The External Building Block - Environment}


Literature points out environment's strong influence on the existence and effectiveness of CE (Guth, and Ginsberg 1990; Zahra 1991). Executives' perceptions of the environment frame their definitions of the issues facing a company (Zahra, and Pearce 1990) and information from the environment stimulates entrepreneurial activities in the form of "precipitating events" (Zahra 1991). As Morris and Paul (1987) put it EO becomes a strategy to deal with the external environment of an organization.

Many conceptualizations of the environment are largely consistent with Dess and Beard's (1984) three dimensions: hostility, dynamism, and complexity. Hostility is characterized by high levels of competition, rare amount of exploitable opportunities, shortages of labour or raw materials, unfavourable demographic trends, severe regulatory restrictions, and remarkable competitive market, and/or product related uncertainties. Dynamism is manifested by the rate, amount, and unpredictability of change in the environment, which are customer tastes, production or service technologies, and the modes of competition (Miller, and Friesen 1978). Focusing on single/dominant business units in or sample, we did not include complexity, which refers to the heterogeneity of, and range of an organization's activities, but rather investigated technological complexity. This dimension defined by Khandwalla (1976) as "the use of very sophisticated and complex operations' technologies with a lot of research and development involved" is more appropriate both for the sample and subject at stake in this paper.

The literature highlights a strong positive relationship between hostility (Covin, and Slevin 1989), dynamism (Zahra 1991) and EO. Moreover, the challenge and pace of technologically complex environmental settings call for an entrepreneurial posture and high-tech companies are expected to pursue entrepreneurship more aggressively (Covin, and Covin 1990). Yet, a reciprocal relationship is also possible, as innovation prompts imitation, entrepreneurial firms may even be partly responsible for the dynamism, hostility, and technological complexity in the environment (Miller, and Friesen 1982). However, following previous research (Covin, and Slevin 1991; Simsek, 
Veiga, and Lubatkin 2007), this paper expects environmental conditions to be more likely to have a stronger impact on EO rather than vice versa. Therefore, we hypothesize that:

H7: Perceived environmental a) hostility, b) dynamism, and c) technological complexity are positively related to $E O$.

\section{Data, Measures, and Method}

\section{Context and Sampling}

Having a constantly growing economy -an annual GDP growth rate of 4.70 percent between 1999-2017-, Turkey ranks as the world's 17th most industrialized economy (Worldbank 2017). Firms have experienced decades-long chronic inflation, the absence of venture capital until recently, and below OECD median figures for public and business $R \& D$ expenditure per capita (OECD 2014).

Moreover, Turkish cultural characteristics are distinct from that of Western cultures (Bruton, Ahlstrom, and Obloj 2008). These characteristics consist of high collectivism, high power distance, high uncertainty avoidance, paternalism, low performance orientation, low future orientation, low humane orientation, low gender egalitarianism, and low societal collectivism (Kabasakal, and Bodur 1998). This generic cultural profile does not comply with the ideal type for entrepreneurship presented in the literature (Hayton, George, and Zahra 2002).

The population of the study consists of firms listed on the Istanbul Chamber of Industry where we as the researchers live in. Moreover, the sample includes firms which had been in existence for at least five years in order to move beyond the threshold of "newness" and thus to reduce the associated potential bias (Covin, and Slevin 1989) and the dominant firms that generate at least 70 percent of their sales from a single industry have potential to be more on the cutting edge of developing CE activities (Rumelt, 1974). 
Finally, our study targets key informants who are better positioned than other managers in terms of knowing their firms' overall operations (Green, Covin, and Slevin 2008) and providing strategy-related information (Hambrick 1981; Zahra 1991). However, this reliance on self-reported data from single informants leaves the analysis open to common method bias (Podsakoff, MacKenzie, Lee, and Podsakoff 2003). Thus, the study utilizes valid, multidimensional constructs, which are carefully finalized through exploratory phase, and contact with assured informants of confidentiality and anonymity to reduce the evaluation apprehension (Podsakoff, MacKenzie, Lee, and Podsakoff 2003). For each variable, we have data through three or less respondents in each firm. Yet, the inter-rater agreement statistics indicates a high degree of agreement suggesting that the results would likely be the same with larger samples of employees from each firm. Harman's single-factor test does not yield to a single factor, and no general factor could account for the majority of variance. Moreover, in the confirmatory factor analysis (CFA), the improvement in the fit statistics of the eleven-factor model over the one-factor model, is highly significant $\left(\Delta \chi^{2}(55\right.$, $N=276)=4,905.03, p<.001)$. In addition, usable secondary responses from 156 firms (45 percent of the total sample) are compiled. In line with past literature (Kumar, Stern, and Anderson 1993), we initially compute the inter-rater agreement index $\left(r_{\mathrm{wg}}\right)$ (James, Demaree, and Wolf 1993) for each construct and for each firm. The medians within group $r_{\mathrm{wg}}$ values for all of the constructs are between .91-.99 while mean values are ranging between .81-.99, both indicating high agreement (Erdogan, Liden, and Kraimer 2006). Moreover, results of the t-tests comparing the primary and secondary informants' mean scores on each research variable reveal no significant differences between these two categories of informants in any of the constructs.

For data collection, we employed a slightly modified version of Dillman's (2000) five-wave mailing methodology. Eventually, in a 19 weeks period, we mailed six different waves and received 520 usable questionnaires from 347 firms out of a sample of 2,040 key informants from 680 firms. This correspond to an effective response rate of 51 percent firm-wise, and 25 percent informantwise, which are well above the typical rate for, studies targeting executives in upper echelons 
(Geletkanycz 1997; Zahra, and Pearce 1990). We assess the likelihood of non-response bias using the extrapolation technique (Armstrong, and Overton 1977). Our analysis indicates no significant $(p<.05)$ differences between any of the groups where we group the respondents into five different clusters and two equal-sized groups are formed of the first and the last quartiles according to mailing waves conducted, the one-way variance analysis conducted based on company location, age, size, turnover, employee number, and shareholder structure. Our complementary analysis regarding t-tests between mean responses on each of the constructs (Covin, and Slevin 1989) confirms this result as well.

\section{Measures}

Following the initial translation and adaptation of the existing scales, for which we follow the guidelines of Brislin (1980). We run a pre-test phase mainly consisting of face-to-face interviews with different groups of respondents (17 managers from 11 different companies and five academicians working in psychology and organizational sciences) in order to clarify the survey format and ensuring content validity. Then, we sent the revised questionnaire through emails to 141 respondents from 88 companies with profiles quite similar to those in the final sample. This pilottest phase where 50 respondents from 32 different firms return the completed surveys, aims to assess the construct as well as the face validity of each measure (in Appendix A, we present the finally used items used for measuring each construct). In all of the scales, higher scores indicated higher levels of the construct.

Organizational Culture: Although it lacks the depth and richness achieved through ethnography, researchers frequently use mail surveys to assess organizational culture (Hofstede, Neuijen, Ohayv, and Sanders 1990; Morris, Avila, and Allen 1993; O'Reilly, Chatman, and Caldwell 1991; Yilmaz, Alpkan, and Ergun 2005). We do the same and use items gathered from Dorfman and Howell, (1988), Morris et al. (1993), Yilmaz et al. (2005), and Zahra et al. (2004) to 
assess collectivism dimension, and seven items from the Sigler and Pearson (2000) and one item from Robbins and Mukerji (1994) to assess power distance.

Being one of the complex concepts of the study, we validate OC constructs by utilizing human resources management practices (Robert and Wasti, 2002). These practices are accepted as an important tool for creating and reinforcing an organization's unique culture (Hayton, George, and Zahra 2005; Schein 1992). Thus, this paper develops human resources validation scales based on a review of the literature (Geletkanycz 1997; Herbig 1994; Robert, and Wasti 2002; Schein 1992; Schneider 1988). Hierarchical human resources practices are significantly positively correlated with organizational power distance $(r=.48, \mathrm{n}=347, \mathrm{p}<.001)$ and negatively correlated with the organizational collectivism $(\mathrm{r}=-.45, \mathrm{n}=345, \mathrm{p}<.001)$. In addition, individualistic human resources practices are significantly negatively correlated with organizational collectivism $(\mathrm{r}=-.53$, $\mathrm{n}=345, \mathrm{p}<.001)$ and positively correlated with the organizational power distance $(\mathrm{r}=.48, \mathrm{n}=346$, $\mathrm{p}<.001)$

Entrepreneurial Orientation: Initially developed by Khandwalla (1977), modified by Miller and Friesen (1982), and finalized by Covin and Slevin (1989), the nine-item EO scale or its slightly modified versions have been the most commonly used measures for CE (Rauch, Wiklund, Lumpkin, and Frese 2009). However, the three dimensions proposed by Miller and Friesen (1982) have not always been evident in every study (Knight 1997). Moreover, Lumpkin and Dess (1996) conceptually discuss the inclusion of autonomy, and competitive aggressiveness dimensions. However, few studies -16 to be specific according to Saha et al.'s (2017) review article- have empirically employed five-dimensional EO measure (Saha, Kumar, Dutta, and Dutta 2017; Wales 2015; Wales, Gupta, and Mousa 2013). This paper aims to clarify the proposed relationships better and provide some "unique insights" to the EO literature (Covin, and Lumpkin 2011; Covin, and Wales 2012; Miller 2011). Thus, we modify the original nine-item scale to include competitive aggressiveness and autonomy constructs with items adapted from Khandwalla (1976), Lumpkin and Dess (2001), Venkatraman (1989), and Shane et al. (1995). 
We need to note here that recent studies (Covin and Wales, 2019) point out that certain qualities such as innovation must exist at a minimum so that a firm could be considered as entrepreneurial. Thus, including innovation as one of the dimensions to measure the EO construct might seem tautological, yet, innovation is examined differently within the EO and CE measures. This paper will treat innovation as one dimension within the uni-dimensional construct of EO, but we suggest further studies to consider the call made by Covin and Wales (2019).

Initially conceptualized as a unidimensional construct, quite big number of followers -three out of every four studies (Wales, Gupta, and Mousa 2013)- analyse EO as a composite variable (Rauch, Wiklund, Lumpkin, and Frese 2009; Wales, Gupta, and Mousa 2013). As such, though the sub-dimensions can vary independently, the formative construct of EO, as proposed by Miller (1983) are expected to be synchronously high in all dimensions. Yet though CE is multidimensional, as we in this study distinctly refine EO as an attitude, we measure EO as a composite construct with its five dimensions. Still, even statistically, when the five-factor model is compared to the one-factor model where all items loaded on one factor, the improvement in the fit statistics is highly significant $\left(\Delta \chi^{2}(78, \mathrm{~N}=273)=5,273.08, \mathrm{p}<.001\right)$. Even though the average variance extracted result for innovativeness dimension is somewhat disappointing, that alone is not significant enough to cause concern considering all the other results. We use a seven-point, doublesided semantic differential-type Likert scale.

Corporate Entrepreneurship: We use Zahra's (1996) scale based on Guth and Ginsberg's (1990) conceptualization to measure CE and modify it with items from Simsek et al. (2007) and Zahra et al. (2000).

Being one of the main constructs of the study, we validate CE scale by objective questions adapted from Eliasson and Davidsson (2003), Keil et al. (2003), and Morris et al. (1994). The analysis reveals three observations. Accordingly, 40 percent of the firms in the sample have not established any independent and/or semi-independent business units in the last three years; 31 percent have not financially supported and/or established new business units; and 50 percent have 
not realized any joint ventures and/or acquisitions in the last three years. Indeed, the venturing dimension has the lowest mean of 2.38 (out of five; standard deviation being 1.07) among all variables. It may be that the highly volatile, "open-to-crisis" nature of the Turkish economy combined with the riskier nature of venturing compared to other types of CE, make firms vulnerable, and results in little venturing activity in the context of Turkey. Therefore, to prevent it from misleading our conclusions we eliminate the venturing dimension from the analysis.

Being close constructs we further factor analyse all EO and CE items simultaneously. In the exploratory factor analysis, just eight factors with eigen-values over one extract, exactly as expected. Moreover, we conduct CFA for the items under "innovation" and "innovativeness" headings in both constructs, to dissociate them statistically as well. The two-factor model compares to one-factor model where all items loaded on one factor. The results demonstrate that the improvement in the fit statistics of the two-factor model over the one-factor model is highly significant $\left(\Delta \chi^{2}(1, \mathrm{~N}=32)=89.05, \mathrm{p}<.001\right)$. In sum, statistical findings reinforce our proposed distinction and categorization.

Managerial Support: For measuring managerial support, we use the scales developed and validated by Hornsby, et al., (2002), and modify it with items from Zahra (1991).

External Environment: We assess three environmental dimensions with items developed and validated by Khandwalla (1976) and Miller and Friesen (1978; 1984). We ask informants to characterize their firms' environment through a total of nine items, utilizing a seven-point Likert scale with semantic differential anchored by descriptive phrases.

Performance: Despite the multidimensional nature of the performance construct (Wiklund, and Shepherd 2005), most empirical research undertaken so far has examined the performance by combining indicators associated with profitability and growth (Moreno, and Casillas 2008). Thus, we utilize measures of both profitability and growth, together with non-financial performance in order to capture the multidimensional nature of performance (Wiklund, and Shepherd 2005). 
The informants are asked to rate the performance of their businesses over the last three years, on a five-point Likert-type scale ranging from "not at all satisfactory" to "outstanding" (Dess, and Robinson 1984; Gupta, and Govindarajan 1984). To integrate different dimensions, informants are requested to estimate three indicators of growth: total sales, market share, and employment, and three indicators of profitability: long-term profitability, operating profit, and profit over capital. To assess non-financial performance, we use four indicators questioning the image and impact on society, customer satisfaction, supplier satisfaction, and employee satisfaction. Incorporating the perceived value created for customers, suppliers and employees into the performance measure is one of the empirical contributions of the study.

Control Variables: Control variables comprising of company size, age, and sector mitigate any potential spurious interpretations of the findings. The company size is measured by the number of the firm's full-time employees (Wiklund, and Shepherd 2005) that is log-transformed for normality while the number of years a firm has been in existence reflects company age (Wiklund, and Shepherd 2005). As companies in different industries face different competitive challenges, causing them to use various approaches (Zahra 1991), we assign companies to one of two groups (service or manufacturing) according to NACE standards. Moreover, the paper utilizes external environment dimensions as control variables for performance.

\section{Results}

\section{Overview}

Initially, we assess composite reliability estimates (Fornell, and Larcker 1981) besides Cronbach's alpha coefficients (Cronbach, and Shavelson 2004). Subsequently, we examine the measurement model following Anderson and Gerbing's (1988) two-step approach. All factors of the proposed model other than the only composite measure of the study, EO, are tested simultaneously while freely correlating with each other. In particular, we check the standardized loadings to see if 
they are significant and higher than the level of 0.5 indicating superior convergent validity (Fornell, and Larcker 1981). Thereafter, discriminant validity is assessed via tests of composite reliability and average variance extracted (Fornell, and Larcker 1981; Shook, Ketchen, Hult, and Kacmar 2004). Finally, because of limitations in the chi-square test (Byrne 2006), we evaluate the overall fit of the model through the measure of chi-square relative to degrees of freedom, and the indices recommended by Shook et al. (2004), namely incremental fit index (IFI), Bentler-Bonett nonnormed fit index (NNFI), the comparative fit index (CFI), and root mean square error of approximation (RMSEA).

Table 1 presents the CFA results with related descriptive statistics of all variables. All composite reliability figures are above the acceptable level; all items load significantly on their respective constructs (with the lowest t-value being 7.71); and all error variances are positive providing support for the convergent validity of measurement items. The fit indices for the second order CFA yielded a $\chi^{2} / \mathrm{df}$ ratio of 1.47 , a CFI of 0.97 , a NNFI of 0.97 , an IFI of 0.97 , and RMSEA of 0.04 , indicating an acceptable fit. Finally, the discriminant validity is adequate, as the average variance extracted for each construct is greater than its squared correlations with other constructs. Whilst the average variance extracted is marginally lower than the acceptable level for five out of 11 variables, we should note that the variance extracted is a complimentary measure only with a purely suggested value.

\section{*** Insert Table 1 about here ***}

Additionally, a second order CFA is conducted for EO which is the only composite measure of the study. In the model, the more specific dimensions are viewed as lower (first) order factors that are presumed to form and cause EO. The fit indices for the second order CFA yielded a $\chi^{2} / \mathrm{df}$ ratio of 1.32 , a CFI of .98 , a NNFI of .98 , an IFI of .98, and RMSEA of .03, indicating a very good fit.

\section{Hypothesis Testing}


We employ a path-analytic model to test the hypotheses. A subset of structural equation modelling, path analysis, is a multivariate procedure that allows examination of a set of relationships between one or more independent variables and one or more dependent variables, either continuous or discrete (Stage, Carter, and Nora 2004). We conduct the analysis for all three dimensions of performance. Figures 2.a, 2.b, and 2.c show the overall structural model with path coefficients and related fit indices while Table 2 presents the parameter estimates of the three models. All the model fit indices seem to reach acceptable threshold levels in four of the five indices. Only in the case of non-financial performance the NNFI fit indices, seem to be marginally below the acceptable level of .90 . However, considering the other indices, the model can be claimed to have a satisfactory fit.

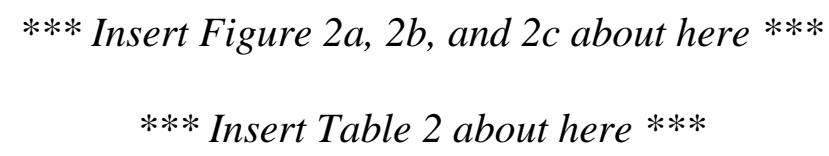

Our results support Hypothesis $1 \mathrm{~b}$, showing a negative association $(\mathrm{p}<.05)$ between power distance and EO. In all the models, our results support Hypothesis 2 proposing a direct positive relation between $\mathrm{EO}$ and all forms of $\mathrm{CE}$, namely innovation and strategic renewal. While the results in relation to innovation dimension is more powerful, all relationships are quite significant (p $<.001)$

Both Hypothesis 3 and 4 receive strong support $(\mathrm{p}<.001)$. While the former highlights the impact of EO on managerial support mechanisms and the latter shows the positive impact of managerial support mechanisms on all forms of CE. There is a strong support for both Hypothesis $5 \mathrm{a}$ and $5 \mathrm{~b}$, demonstrating a strong association $(\mathrm{p}<.001)$ between all cultural dimensions and managerial support.

In the case of Hypothesis 6, the results support that innovation form of CE is positively and strongly $(\beta=.29-.35, \mathrm{p}<.001)$ related to performance in all models. In the non-financial performance model, the positive association $(\beta=.14, \mathrm{p}<.05)$ extends to strategic renewal form as well. 
Finally, confirming Hypothesis 7c, the results show a positive relationship $(p<.01)$ between technological complexity and EO. Moreover, in the profitability performance model, there is a positive relationship $(\mathrm{p}<.05)$ between dynamic external environment and performance. These results show how different type of external environment factors exert a direct influence on performance: while technological complexity increases EO that lead into higher CE behavior and ultimately higher performance, dynamic environment acts as a control variable resulting in higher performance regardless of company's CE activities.

Consequently, we argue that EO serves as a mediating variable between power distance and technological complexity, and all forms of $\mathrm{CE}$ while managerial support shares the same role between OC and all forms of CE. Overall, the study demonstrates the important antecedent role of $\mathrm{EO}$ and managerial support on $\mathrm{CE}$ forms, especially innovation, and the mediating role of $\mathrm{CE}$ between these two antecedents and performance.

\section{Discussion and Conclusion}

The main goal of the study is to develop a more solid understanding of the firm-level entrepreneurship and performance relationship, claimed to be pervaded by a black box (Dess, Ireland, Zahra, Floyd, Janney, and Lane 2003) and explore the interconnection between different variables of this relationship which is still claimed to have "definitional inconsistencies" (Randerson 2016). Following the Schumpeterian basics enriched with the "the value-attitudebehavior cognitive hierarchy model" theorization of Social Psychology, our model re-constructs the relationship. Moreover, by distinguishing and distilling the roles of different variables, our proposed model re-allocates constructs in the equation in a more robust and solid following order: OC, together with environment, represents the "value" set that induces an entrepreneurial "attitude" in the form of EO, and this attitude transforms into some concrete form of "intentions" (managerial support mechanisms) triggering CE behavior. Our empirical study strongly confirms our theoretical model and shows a strong positive impact of $\mathrm{CE}$ on performance. 
The study is one of the rare studies with empirical observation of the role of OC that is widely discussed in literature (Covin, and Slevin 1991; Fayolle, Basso, and Bouchard 2010; Lumpkin, and Dess 1996). The findings verify conceptual expectations by showing how OC directly affects EO and managerial support. In addition, the study confirms previous findings (Hornsby, Kuratko, and Montagno 1999; Hornsby, Kuratko, and Zahra 2002) about the strong association between CE and senior executives' support. Albeit, external environment seems to have a limited role in our model compared to previous studies in the literature (Zahra, 1991), our findings show a positive impact of technological complexity on EO as well as positive association between dynamic environment and profitability. The implications are discussed below.

\section{Implications for Theory}

The interdisciplinary approach of our study grounded on a solid theory from Social Psychology besides fulfilling this shortfall Zahra, Randerson, and Fayolle (2013) draw attention, enrich CE literature in three ways.

First, our findings confirm our argument about the literature's overlook to the behavior itself even though Schumpeter (1934), who can claimed to be the first person who put forward entrepreneur into the economic scene, stated an organization will be entrepreneurial only if it fulfills the "function" not when it has non-behavioral firm-level attributes. Correct hierarchical order of relationship between $\mathrm{CE}$ and $\mathrm{EO}$, provides a more solid relationship of $\mathrm{CE}$ and performance. This proposition helps improving the still "debated" conceptualization of EO (Covin and Wales 2019).

Moreover, our model differentiates the effects of different CE dimensions. We find that CE in the form of innovation has positive impact on all types of performance while CE in the form of strategic renewal seems to affect non-financial performance directly and positively. It may be that the larger scale of the dimension itself that demands more investment in terms of money and time ends up with the lagged performance effect on profitability and even growth. In the case of nonfinancial performance which is partly related to the image and perceptions created, the outcome 
seems to be more easily and quickly realizable. Indeed, these varying results for different $\mathrm{CE}$ dimensions is another supportive sign of using the CE behavior rather than EO for the assessment of firm-level entrepreneurial behavior.

Second, this differentiation of $\mathrm{CE}$ and EO helps us to observe the relationship between EO and different $\mathrm{CE}$ behavior. In our study, EO has positive impact on both innovation and strategic renewal with varying degrees of impact.

Third, putting the variables into a correct hierarchical order of relationship helps to recognize the role of OC. We clearly find out positive impact of OC as the antecedent of CE. However, the study further shows OC exerts its influence indirectly through EO and managerial support. Values (OC) and attitudes (EO) might not necessarily result in actual behavior, so it becomes critical to identify a mechanism that could mediate the relationship between OC and CE as well as between $\mathrm{EO}$ and CE. This mechanism in our study is managerial support.

In addition, the paper makes three minor extensions to empirical studies in CE. Measuring EO in five dimensions may be one of the plausible explanations of strong connection between EO and CE. Incorporating non-financial performance dimension has shown its value in the results. Our findings confirm the multi dimensionality of the performance variable. Finally, the empirical study takes place in an emerging economy context that is less studied in the CE literature.

\section{Implications for Practice}

The findings indicate that managers must manipulate the organizational support, reward, and recognition mechanisms to create an organizational context that supports and helps to sustain and increase CE behavior. In other words, the attitude should come into existence in the form of some support to transform into CE behavior. As the findings demonstrate, high managerial support will pay off considerably in creating and promoting entrepreneurial behavior. Besides being high on power distance, the Turkish culture hosts highly paternalistic values. These values may have 
amplified the role of managerial support as a powerful direct antecedent of CE behavior, in this context as well.

$\mathrm{OC}$ in the form of both high collectivism (reflected by more cooperation and collaboration) has a high positive association with managerial support activities. The power distance dimension of OC seems to have a relatively important association with both EO and managerial support. Promoting human resources management practices that reflect and signal low power distance is likely to increase perceptions of managerial support and the prevalence of EO.

Theoretically, an emerging economy context with unstable economic environmental conditions would strengthen the impact of dynamism and hostility while the effect of technological complexity would stay low compared to that of advanced countries due to the low level of comparable technological complexity. However, the results revealed exactly the opposite. Technological sophistication had the strongest effect on EO, and although dynamism had some significant effects when the dependent variable was profitability, none of the hostility related hypotheses were supported. It could be that firms operating in a complex environment accompanied by minor or major crises for a long time are accustomed to hostile and dynamic conditions, whereas, in the context of comparatively low levels of technological sophistication, firms with relatively more technological sophistication create a difference. Therefore, firms operating in countries comparable to Turkish economy might experience limited impact of environmental factors in their CE activities compared to what literature on advanced economies find strong relationship (Zahra 1991).

\section{Limitations and Further Study}

In addition to two basic limitations inherent in most research, namely survivor bias (Sykes 1986) and the issue of generalizability which we try to overcome with broad representation of types and sizes of businesses in our sample, we summarize five limitations below. 
First, among the limitations of this study is the reliance on self-report items in measuring most of the variables. Measurement of different variables by different respondents or through archival or objective data could have yielded results that are more powerful. However, other than some practical issues as in the case of performance measures, we mainly prefer perceptual measures as top managers' entrepreneurial inclinations, strategy-shaping perceptions, and support mechanisms form the backbone of this study. This is because perceptions might override factual characteristics of the environment and influence strategic behavior, rather than what is going on actually in practice (Schneider 1989; Spanos, and Lioukas 2001).

Second limitation arises from financial figures. Varying accounting conventions or managerial manipulations try to avoid corporate or personal taxes, etc. (Dess, and Robinson 1984) are already acknowledged rationales about unreliability of reported figures' in the literature. Moreover, in economies like Turkey, where about a third of the economy operates unregistered ${ }^{1}$ and firms have operated under high chronic inflation for decades: an average of 55 percent for the last 25 years (Bayraktutan, and Arslan 2009), perceptual measures constitute even more reliable and conventional way for assessing firm performance. Nevertheless, Chandler and Hanks (1993) show that owner/CEO assessments of business activity are highly correlated with archival data. Supportively, researchers (Dess, and Robinson 1984; Heneman 1974) advise the utilization of perceptual measures where accurate objective measures are not available, and the alternative is to remove the performance from the research design.

Third limitation is the measurement of OC only through three or less respondents in each firm. Yet, as discussed in the methods section, the statistical tests show how this limitation has not been a big concern for our constructs.

Fourth limitation is the study's short time frame, which did not permit an analysis of causal relationships among the variables. In a longitudinal study, results could have confirmed the positive association of strategic renewal with other dimensions of performance besides non-financial performance as well. The cross-sectional data does not allow causal inferences about the 
longitudinal interplay among $\mathrm{OC}, \mathrm{EO}, \mathrm{CE}$, and performance; especially the interplay between $\mathrm{CE}$ and performance. However, as previously asserted in the literature (Covin, and Slevin 1989), a reverse relationship is not highly plausible.

Last but not the least, though we mainly try to test our new formulation based on hierarchical ordering of concepts in a comprehensive model, exclusion of some organizational parameters like organizational structure, might have brought some more variation into our model.

Overall, cautious interpretation should be in order. However, despite its limitations, we hope that the evidence presented in this study will inspire future interest and encourage validation of the ideas presented. Further empirical tests on the mediating role of $\mathrm{CE}$ in various contexts can confirm this study's formulation.

Then, it will be more meaningful to examine the other possible antecedents, moderators, mediators of the relationship of firm-level entrepreneurship. Moreover, EO construct's each dimension could be individually examined to observe how each one of them are driving observed effects in the CE behavior and the resulting performance. Finally, following the call of Covin and Wales (2019), researchers might even develop new EO definitions and constructs that could improve our understanding of CE.

\footnotetext{
${ }^{1}$ In addition to a formal economy, Turkey has a large informal one that reached 45 percent of the average GNP for the period of 1968-2001. Though in recent years this ratio has decreased, a shadow economy still has been estimated to reach 30 percent, during the 1990-2003 period Schneider, F. (2007).
} 
Figure 1

Proposed Model of Corporate Entrepreneurship

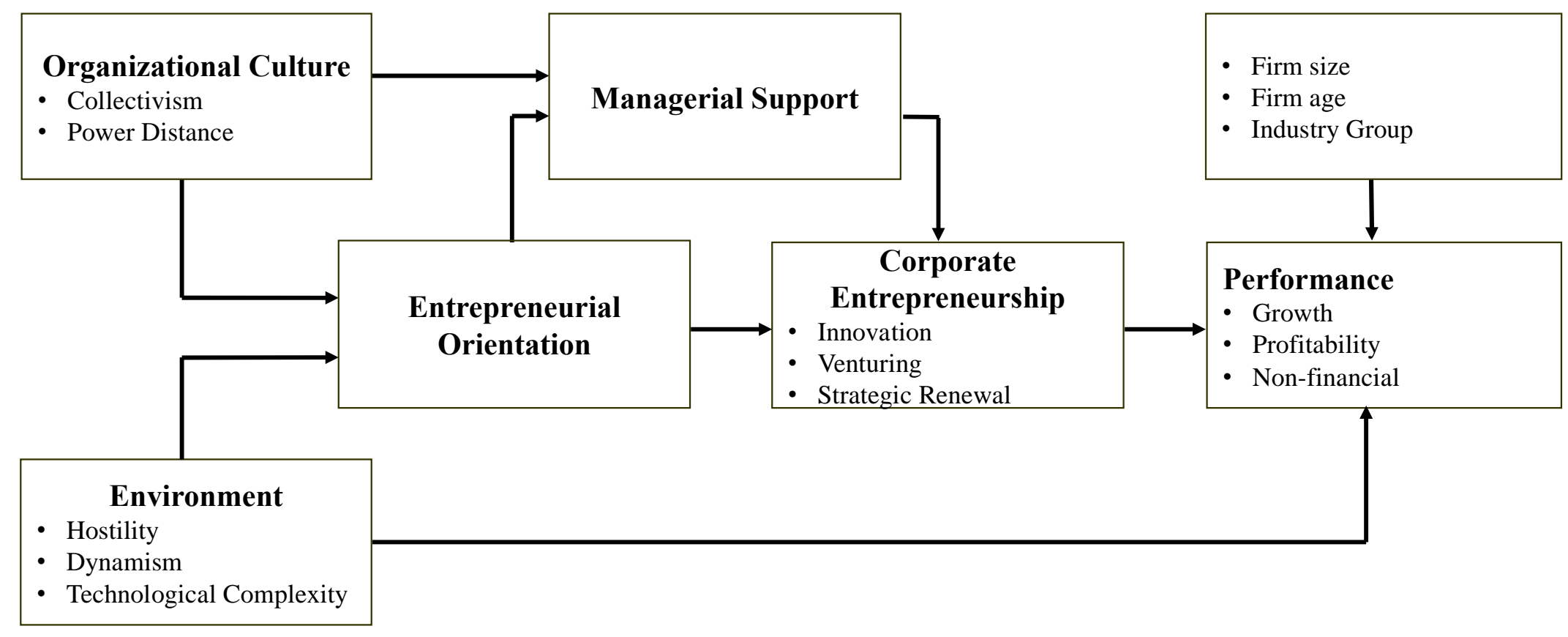




\section{Table 1}

\section{Correlations $^{\text {a }}$, Descriptive Statistics, and Measurement Model Results ${ }^{\text {b }}$}

\begin{tabular}{|c|c|c|c|c|c|c|c|c|c|c|c|c|c|c|c|c|c|c|c|c|c|c|}
\hline Variables & $\begin{array}{l}\text { \# of } \\
\text { items }\end{array}$ & Alpha & $\begin{array}{l}\text { Composite } \\
\text { Reliability }\end{array}$ & 1 & 2 & 3 & 4 & 5 & 6 & 7 & 8 & 9 & 10 & 11 & 12 & 13 & 14 & 15 & 16 & 17 & 18 & 19 \\
\hline $1 \mathrm{Age}$ & 1 & & & 1 & & & & & & & & & & & & & & & & & & \\
\hline 2 Number of Employees (log) & 1 & & & $0.31^{* * * * *}$ & 1 & & & & & & & & & & & & & & & & & \\
\hline 3 Hostility & 3 & 0,76 & 0,72 & 0.03 & 0.07 & 0,47 & 0,26 & 0,06 & 0,01 & 0,01 & 0,01 & 0,00 & 0,01 & 0,02 & 0,01 & 0,02 & & & & & & \\
\hline 4 Dynamism & 3 & 0,73 & 0,70 & 0.03 & 0.08 & $0.51^{* * * * *}$ & 0,44 & 0,10 & 0,01 & 0,03 & 0,01 & 0,01 & 0,03 & 0,01 & 0,00 & 0,00 & & & & & & \\
\hline 5 Technological Complexity & 3 & 0,71 & 0,78 & 0.03 & $0.23 * * * *$ & $0.25 * * * *$ & $0.32 * * * \mid$ & 0,54 & 0,03 & 0,05 & 0,06 & 0,07 & 0,09 & 0,00 & 0,01 & 0,00 & & & & & & \\
\hline 6 Collectivism & 7 & 0,91 & 0,91 & -0.07 & 0.06 & 0.08 & $0.10 \dagger$ & $0.18 * * *$ & 0,60 & 0,24 & 0,05 & 0,16 & 0,32 & 0,02 & 0,13 & 0,01 & & & & & & \\
\hline 7 Power Distance & 8 & 0,86 & 0,87 & 0.08 & -0.08 & $-0.10 \dagger$ & $\mid-0.16 * *$ & $|-0.22 * * * *|$ & $-0.49 * * * *$ & 0,46 & 0,08 & 0,11 & 0,27 & 0,02 & 0,09 & 0,01 & & & & & & \\
\hline 8 Innovation & 6 & 0,91 & 0,91 & -0.03 & $0.14 * *$ & $-0.11^{*}$ & 0.11 * & \begin{tabular}{|l|l|}
$0.24 * * * *$ \\
\end{tabular} & $0.23 * * *$ & $-0.29 * * *$ & 0,63 & 0,31 & 0,17 & 0,10 & 0,15 & 0,13 & & & & & & \\
\hline 9 Strategic Renewal & 5 & 0,83 & 0,79 & -0.06 & $0.24 * * * *$ & -0.02 & 0.08 & $0.27 * * *$ & $0.39 * * *$ & $-0.33^{* * * *}$ & $0.55 * * *$ & 0,44 & 0,29 & 0,02 & 0,08 & 0,08 & & & & & & \\
\hline 10 Managerial Support & 7 & 0,85 & 0,86 & -0.04 & $0.12^{*}$ & 0.09 & $0.16 * *$ & 0.31 ***** & $0.57 * * *$ & $-0.51 * * * *$ & $0.41 * * *$ & $0.54 * * *$ & 0,48 & 0,03 & 0,17 & 0,03 & & & & & & \\
\hline 11 Profitiability Performance & 3 & 0,91 & 0,91 & 0.04 & 0.09 & $-0.15 * * \mid$ & -0.08 & -0.07 & $0.14 *$ & $-0.15 * *$ & $0.32^{* * * * *}$ & $0.15^{* * *}$ & $0.16 * *$ & 0,78 & 0,19 & 0,34 & & & & & & \\
\hline 12 Non-Financial Performance & 4 & 0,84 & 0,85 & -0.04 & -0.02 & $-0.09 \dagger$ & 0.01 & $0.12^{*}$ & $0.36 * * *$ & $-0.30^{* * * * *}$ & $0.39 * * * *$ & $0.28 * * *$ & $0.42^{* * * * *}$ & $0.44 * * *$ & 0,59 & 0,17 & & & & & & \\
\hline 13 Growth Performance & 3 & 0,74 & 0,77 & $-0.11 \dagger$ & $0.11 \uparrow$ & $-0.13^{*}$ & -0.03 & 0.01 & $0.10 \dagger$ & $-0.12^{*}$ & $0.35 * * * *$ & $0.28 * * *$ & $0.18 * * * *$ & $0.58 * * *$ & $0.41^{* * * * *}$ & 0,53 & & & & & & \\
\hline 14 Entrepreneurial Orientation & 15 & & & -0.01 & $0.21 * * * *$ & $0.15^{* * *}$ & $0.22 * * *$ | & $0.28 * * *$ & $0.17 * * *$ & $-0.26^{* * * * *}$ & $0.54 * * * *$ & $0.41^{* * * *}$ & $0.35^{* * * * *}$ & $0.18 * * *$ & $0.22 * * *$ & $0.22 * * *$ & 1 & & & & & \\
\hline Innovativeness & 3 & 0,72 & 0,72 & -0.01 & $0.25 * * *$ & $0.16^{* * *}$ & $|0.24 * * *|$ & $0.44 * * * *$ & $0.20^{* * * *}$ & $-0.26 * * *$ & $0.52^{* * * * *}$ & $0.40 * * *$ & $0.35^{* * * * *}$ & $0.10 \dagger$ & $0.24 * * * *$ & 0.21 **** & 0.76 **** & 0,46 & 0,22 & 0,12 & 0,07 & 0,02 \\
\hline Proactivity & 3 & 0,77 & 0,79 & 0.02 & $0.09 \dagger$ & -0.01 & 0.08 & $0.18^{* * * *}$ & $0.16^{* * *}$ & $|-0.25 * * *|$ & $0.53 * * * *$ & $0.25^{* * * *}$ & $0.29^{* * * * *}$ & $0.23 * * *$ & $0.29 * * *$ & $0.18^{* * *}$ & $0.66 * * *$ & $0.47 * * * *$ & 0,56 & 0,05 & 0,02 & 0,01 \\
\hline Risk Taking & 3 & 0,74 & 0,75 & -0.04 & $0.11 *$ & 0.04 & $0.10 \dagger$ & $0.13^{*}$ & 0.06 & $-0.10 \dagger$ & $0.26 * * * *$ & $0.21 * * *$ & $0.14 * *$ & $0.11 \dagger$ & $0.13 *$ & $0.15 * *$ & $0.66 * * *$ & $0.35 * * * *$ & $0.23 * * *$ & 0,50 & 0,03 & 0,05 \\
\hline Competitive Aggressiveness & 3 & 0,73 & 0,74 & 0.04 & $0.15 * *$ & $0.20 * * * *$ & $0.12^{*}$ & 0.07 & -0.01 & -0.02 & $0.13 *$ & $0.23 * * *$ & 0.05 & 0.03 & $-0.10 \dagger$ & 0.04 & 0.56 **** & $0.27 * * *$ & $0.13 *$ & $0.18 * * *$ & 0,50 & 0,02 \\
\hline Autonomy & 3 & 0,72 & 0,76 & -0.07 & 0.04 & \begin{tabular}{|l|l|}
0.09 \\
\end{tabular} & $0.13^{*}$ & -0.03 & 0.11 * & \begin{tabular}{|c|}
-0.14 \\
\end{tabular} & $0.14 *$ & $0.13^{*}$ & $0.23 * * * *$ & 0.04 & 0.07 & 0.03 & $0.42 * * *$ & $0.14 * *$ & 0.07 & $0.23 * * *$ & $0.14 * *$ & 0,51 \\
\hline Mean & & & & 34,70 & 2,72 & 5,11 & 4,20 & 4,61 & 3,51 & 2,72 & 3,14 & 3,11 & 3,24 & 3,45 & 3,75 & 3,47 & 4,04 & 4,59 & 4,89 & 3,75 & 3,87 & 3,11 \\
\hline Standart Deviation & & & & 18,71 & 0,53 & 1,10 & 1,24 & 1,36 & 0,74 & 0,73 & 0,91 & 0,85 & 0,73 & 0,92 & 0,75 & 0,80 & 0,74 & 1,29 & 1,33 & 1,26 & 1,18 & 0,82 \\
\hline
\end{tabular}




\section{Figure 2.a}

Path Model - Growth as the Dependent Variable

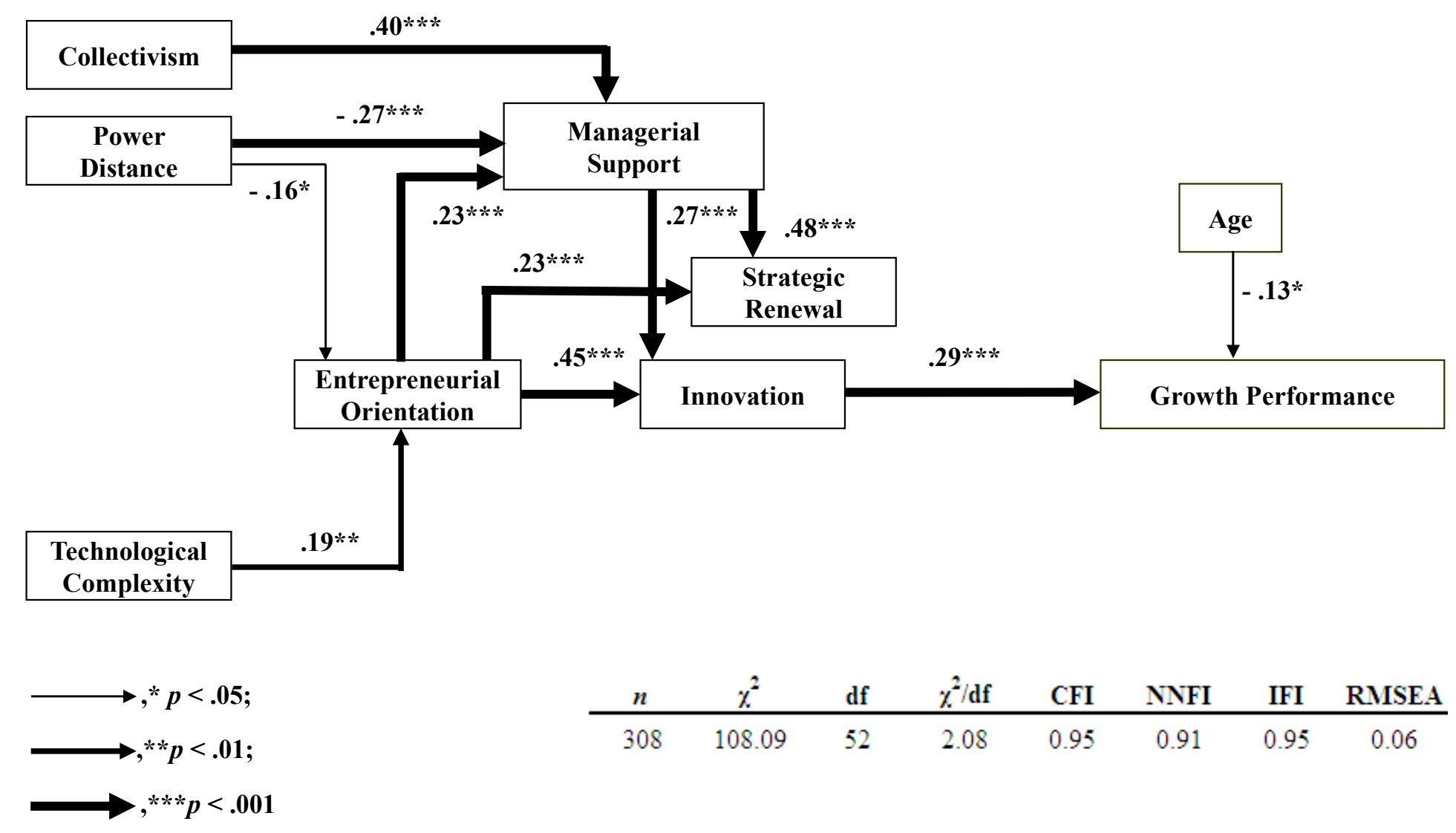




\section{Figure 2.b}

\section{Path Model - Profitability as the Dependent Variable}
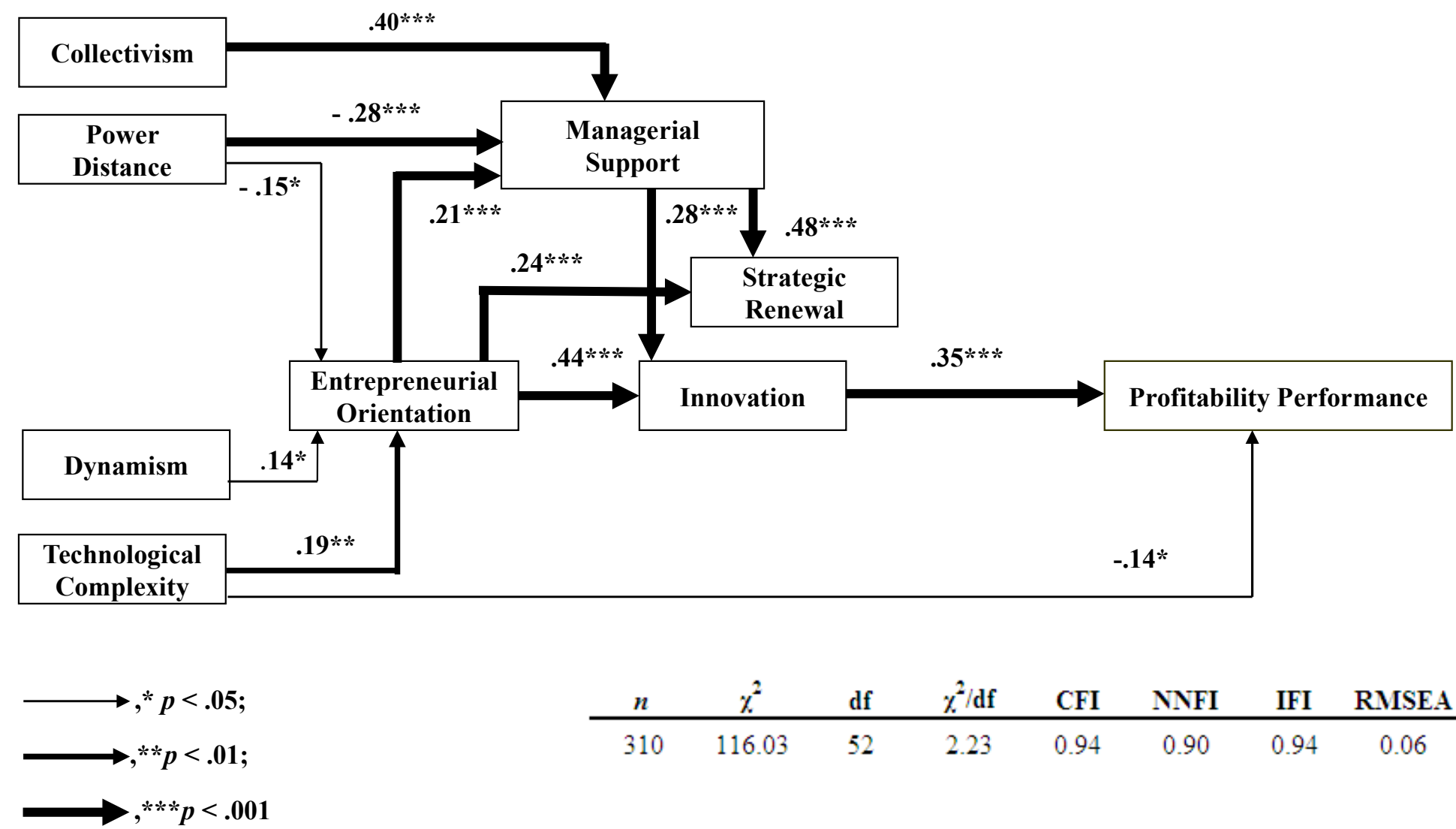

\begin{tabular}{cccccccc}
$n$ & $\chi^{2}$ & df & $\chi^{2} /$ df & CFI & NNFI & IFI & RMSEA \\
\hline 310 & 116.03 & 52 & 2.23 & 0.94 & 0.90 & 0.94 & 0.06
\end{tabular}




\section{Figure 2.c}

Path Model - Growth as the Dependent Variable

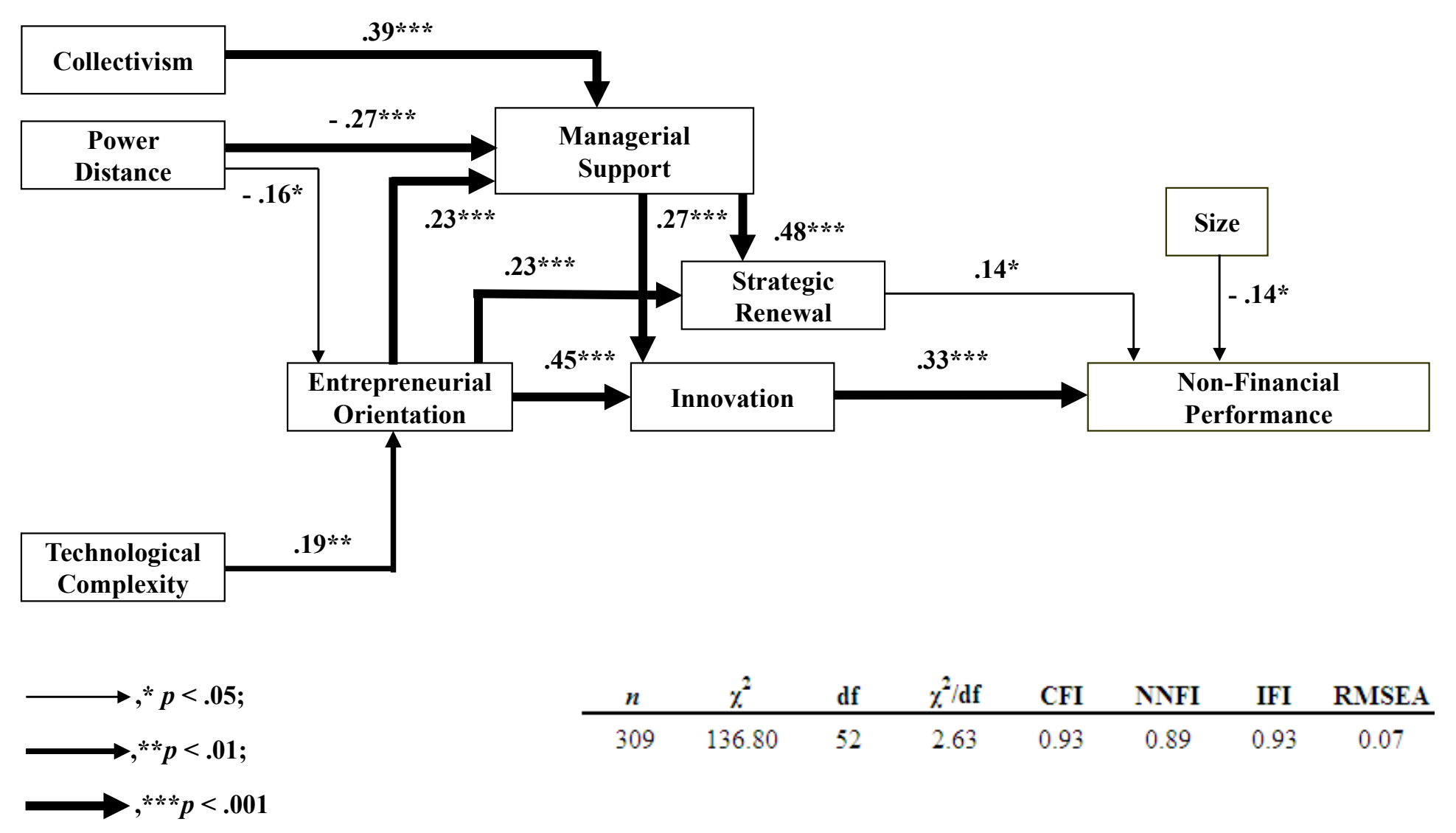


Table 2

Path Analysis Results: Goodness of Fit Indices

\begin{tabular}{l|cccccccc} 
& $\boldsymbol{n}$ & $\boldsymbol{\chi}^{\mathbf{2}}$ & $\mathbf{d f}$ & $\boldsymbol{\chi}^{\mathbf{2}} / \mathbf{d f}$ & $\mathbf{C F I}$ & NNFI & IFI & RMSEA \\
\hline Growth Performance & 308 & 108.09 & 52 & 2.08 & 0.95 & 0.91 & 0.95 & 0.06 \\
Profitability Performance & 310 & 116.03 & 52 & 2.23 & 0.94 & 0.90 & 0.94 & 0.06 \\
Non-financial Performance & 309 & 136.80 & 52 & 2.63 & 0.93 & 0.89 & 0.93 & 0.07 \\
\hline
\end{tabular}




\section{References}

Ajzen, I. 1991. "The Theory of Planned Behavior." Organizational Behavior and Human Decision Processes 50(2): 179-211.

Andersen, J. C. and Gerbing, D. W. 1988. "Structural Equation Modeling in Practice." Psychological Bulletin 103(3): 411-423.

Armstrong, J.S. and Overton, T.S. 1977. "Estimating Nonresponse Bias in Mail Surveys." Journal of Marketing Research 14(3): 396-402.

Atuahene-Gima, K., \& Ko, A. 2001. An empirical investigation of the effect of market orientation and entrepreneurship orientation alignment on product innovation. Organization Science, 12(1): 5474.

Aycan, Z. 2001. "Human Resource Management in Turkey." International Journal of Manpower 22(3): 252-260.

Baker, W. E. and Sinkula, J. M. 2009. "The Complementary Effects of Market Orientation and Entrepreneurial Orientation on Profitability in Small Businesses." Journal of Small Business Management 47(4): 443-464.

Barney, J.B. 1986. "Organizational Culture.” Academy of Management Review 11(3): 656-665.

Barringer, B. R., and Bluedorn, A. C. 1999. "The Relationship Between Corporate Entrepreneurship and Strategic Management." Strategic Management Journal, 20: 421-444.

Bayraktutan, Y. and Arslan, I. 2009. "Sources of Economic Instability in Turkey (1990-2008):" Gaziantep University Journal of Social Sciences 8(1): 199-213.

Brettel, M., Chomik, C. and Flatten, T.C. 2015. "How Organizational Culture Influences Innovativeness, Proactiveness, and Risk-Taking." Journal of Small Business Management 53(4): 868-85.

Brislin, R. 1980. "Translation and Content Analysis of Oral and Written Materials." in Handbook of Cross-Cultural Psychology. Eds. H. C. Triandis and J. W. Berry. Boston: Allyn and Bacon, 389-444.

Bruton, G. D., Ahlstrom, D. and Obloj, K. 2008. "Entrepreneurship in Emerging Economies." Entrepreneurship Theory and Practice 32(1): 1-14.

Burgelman, R.A. 1983. "Corporate Entrepreneurship and Strategic Management): Insights from a Process Study." Management Science 29(12): 1349-1364.

Byrne, B. M. 2006. Structural Equation Modeling with Eqs. Mahwah, NJ): Lawrence Erlbaum.

Cameron, K., and Quinn, R. 2006. Diagnosing and changing organizational culture. Based on the competing values framework. San Francisco, CA: Jossey-Bass. 
Chandler, G.N. and Hanks, S.H. 1993. "Measuring the Performance of Emerging Businesses): A Validation Study." Jounal of Business Venturing 8(5): 391-408.

Cherchem, N. 2017. "The Relationship between Organizational Culture and Entrepreneurial Orientation in Family Firms." Journal of Family Business Strategy 8(2): 87-98.

Covin, J.G. and Covin, T.J. 1990. "Competitive Aggressiveness, Environmental Context, and Small Firm Performance.” Entrepreneurship Theory and Practice 14(4): 35-50.

Covin, J.G. and Slevin, D.P. 1989. "Strategic Management of Small Firms in Hostile and Benign Environments." Strategic Management Journal 10(1): 75-87.

--- 1991. "A Conceptual Model of Entrepreneurship as Firm Behavior." Entrepreneurship Theory and Practice 16(1): 7-25.

Covin, J. G. and Lumpkin, G. T. 2011. "Entrepreneurial Orientation Theory and Research." Entrepreneurship Theory and Practice 35(5): 855-872.

Covin, J. G. and Wales, W. J. 2012. "The Measurement of Entrepreneurial Orientation." Entrepreneurship Theory and Practice 36(4): 677-702.

Covin, J. G. and Wales, W. J. 2019. Crafting High-Impact Entrepreneurial Orientation Research: Some Suggested Guidelines. Entrepreneurship Theory \& Practice, 43(1), 3-18.

Cronbach, L.J. and Shavelson, R.J. 2004. "My Current Thoughts on Coefficient Alpha and Successor Procedures." Educational and Psychological Measurement 64(3): 391-418.

Dess, G.G. and Beard, D.W. 1984. "Dimensions of Organizational Task Environments." Administrative Science Quarterly 29(1): 52-73.

Dess, G.G., Ireland, R.D., Zahra, S.A., Floyd, S.W., Janney, J.J. and Lane, P.J. 2003. "Emerging Issues in Corporate Entrepreneurship." Journal of Management 29(3): 351-378.

Dess, G.G. and Robinson, R. B., Jr. 1984. "Measuring Organizational Performance in the Absence of Objective Measures." Strategic Management Journal 5(3): 265-273.

Detert, J.R., Schroeder, R.G. and Mauriel, J.J. 2000. "A Framework for Linking Culture and Improvement Initiatives in Organizations." Academy of Management Review 25(4): 850-863.

Dillman, D. A. 2000. Mail and Telephone Surveys. New York: John Wiley and Sons.

Dorfman, P. and Howell, J. 1988. Dimensions of National Culture and Effective Leadership Patterns. Greenwich, CT): JAI Press.

Earley, P. C. 1989. "Social Loafing and Collectivism.” Administrative Science Quarterly 34(4): 565581.

--- 1993. "East Meets West Meets Mideast: Further Explorations of Collectivistic and Individualistic Workgroups." Academy of Management Journal 36(2): 319-348. 
Earley, P.C. and Gibson, C.B. 1998. "Taking Stock in our Progress on Individualism-Collectivism: 100 Years of Solidarity and Community." Journal of Management, 24(3), 265-304.

Eliasson, C. and Davidsson, P. 2003. "Entrepreneurial Management, Corporate Venturing, and Financial Performance.." in Frontiers of Entrepreneurship Research. Eds. W. D. Bygrave, C. G. Brush, M. Lerner, P. Davidsson, G. D. Meyer, J. Fiet, J. Sohl, P. G. Greene, A. Zacharakis and R. T. Harrison. Wellesley, MA): Babson College.

Engelen, A., Flatten, T. C., Thalmann, J. and Brettel, M. 2014. "The Effect of Organizational Culture on Entrepreneurial Orientation." Journal of Small Business Management 52(4): 732-752.

Erdogan, B., Liden, R.C. and Kraimer, M.L. 2006. "Justice and Leader-Member Exchange." Academy of Management Journal 49(2): 395-406.

Fayolle, A., Basso, O. and Bouchard, V. 2010. "Three Levels of Culture and Firms' Entrepreneurial Orientation." Entrepreneurship \& Regional Development 22(7-8): 707-730.

Fishbein, M. and Ajzen, I. 1975. Belief, Attitude, Intention, and Behavior): An Introduction to Theory and Research. Reading, MA: Addison-Wesley.

Fornell, C. and Larcker, D. F. 1981. "Evaluating Structural Equation Models with Unobservable Variables and Measurement Error." Journal of Marketing Research 18(1): 39-50.

Gartner, W.B. 1988. ""Who Is an Entrepreneur?" Is the Wrong Question." American Journal of Small Business 12(4): 11-32.

Geletkanycz, M. A. 1997. "The Salience of 'Culture's Consequences'." Strategic Management Journal 18(8): 615-634.

Green, K.M., Covin, J.G. and Slevin, D. P. 2008. "Exploring the Relationship between Strategic Reactiveness and Entrepreneurial Orientation." Journal of Business Venturing 23(3): 356-383.

Gupta, A.K. and Govindarajan, V. 1984. "Business Unit Strategy, Managerial Characteristics, and Business Unit Effect." Academy of Management Journal 27(1): 25-41.

Guth, W.D. and Ginsberg, A. 1990. "Guest Editors' Introduction): Corporate Entrepreneurship." Strategic Management Journal 11(4): 5-15.

Hambrick, D.C. 1981. "Environment, Strategy and Power within Top Management Teams." Administrative Science Quarterly 26(2): 235-275.

Hayton, J.C., George, G. and Zahra, S.A. 2002. "National Culture and Entrepreneurship." Entrepreneurship Theory and Practice 26(4): 33-53.

--- 2005. "Promoting Corporate Entrepreneurship through Human Resource Management Practices." Human Resource Management Review 15(1): 21-41.

Heneman, H.G., III. 1974. "Comparisons of Self and Superior Ratings of Managerial Performance." Journal of Applied Psychology 59(5): 638-642. 
Herbig, P.A. 1994. The Innovation Matrix. Westport, CT: Quorum Books.

Hofstede, G. 1980. Culture's Consequences. Beverly Hills: Sage.

Hofstede, G., Neuijen, B., Ohayv, D.D. and Sanders, G. 1990. "Measuring Organizational Cultures." Administrative Science Quarterly 35(2): 286-316.

Homer, P. M. and Kahle, L. R. 1988. "A Structural Equation Test of the Value-Attitude-Behavior Hierarchy." Journal of Personality and Social Psychology 54(4): 638-646.

Hornsby, J.S., Kuratko, D.F. and Montagno, R.V. 1999. "Perception of Internal Factors for Corporate Entrepreneurship." Entrepreneurship Theory and Practice 24(2): 9-24.

Hornsby, J.S., Kuratko, D.F., Shepherd, D.A. and Bott, J.P. 2009. "Managers' Corporate Entrepreneurial Actions." Journal of Business Venturing 24(3): 236-247.

Hornsby, J.S., Kuratko, D.F. and Zahra, S.A. 2002. "Middle Managers' Perception of the Internal Environment for Corporate Entrepreneurship.” Journal of Business Venturing 17(3): 253-273.

James, L.R., Demaree, R.G. and Wolf, G. 1993. "Rwg: An Assessment of within-Group Interrater Agreement." Journal of Applied Psychology 78(2): 306-309.

Kabasakal, H. and Bodur, M. 1998. "Leadership Values and Institutions." in Research Papers. Istanbul): Bogazici University.

Kandemir, D., Yaprak, A. and Cavusgil, S. T. 2006. "Alliance Orientation." Journal of the Academy of Marketing Science 34(3): 346.

Keil, T., Maula, M. and Schildt, H. 2003. "Corporate Venturing Modes and Their Impact on Corporate Learning." in Frontiers of Entrepreneurship Research. Wellesley, MA: Babson College.

Khandwalla, P.N. 1976. "Some Top Management Styles, Their Context and Performance." Organization and Administrative Sciences 7(4): 21-51.

--- 1977. The Design of Organizations. New York): Harcourt Brace Jovanovich.

Kilmann, R.H., Saxton, M.J. and Serpa, R. 1985. Gaining Control of the Corporate Culture. San Francisco, CA): Jossey-Bass.

Knight, G.A. 1997. "Cross-Cultural Reliability and Validity of a Scale to Measure Firm Entrepreneurial Orientation." Journal of Business Venturing 12(3): 213-225.

Kreiser, P.M., Marino, L.D. and Weawer, K.M. 2002. "Assessing the Psychometric Properties of Entrepreneurial Orientation Scale." Entrepreneurship Theory and Practice 23(3): 71-94.

Kreiser, P.M., Marino, L. D., Dickson, P. and Weaver, K. M. 2010. "Cultural Influences on Entrepreneurial Orientation." Entrepreneurship Theory and Practice 34(5): 959-983.

Kumar, N., Stern, L. W. and Anderson, J. C. 1993. "Conducting Interorganizational Research Using Key Informants." Academy of Management Journal 36(6): 1633-1651. 
Lumpkin, G.T. and Dess, G.G. 1996. "Clarifying the Entrepreneurial Orientation Construct and Linking It to Performance." Academy of Management Review 21(1): 135-172.

--- 2001. "Linking Two Dimensions of Entrepreneurial Orientation to Firm Performance." Journal of Business Venturing 16, 429-451.

Miller, D. 1983. "The Correlates of Entrepreneurship in Three Types of Firms." Management Science 29(7): 770-791.

--- 2011. "Miller (1983) Revisited: A Reflection on EO Research and Some Suggestions for the Future." Entrepreneurship Theory and Practice 35(5): 873-894.

Miller, D. and Friesen, P.H. 1978. "Archetypes of Strategy Formulation." Management Science 24(9): 921-933.

--- 1982. "Innovation in Conservative and Entrepreneurial Firms." Strategic Management Journal 3(1): $1-25$.

--- 1984. Organizations: A Quantum View. Englewood Cliffs): Prentice-Hall.

Mintzberg, H. 1973. "Strategy Making in Three Modes." California Management Review 16(2): 4453.

Mole, K.F. and Mole, M. 2010. "Entrepreneurship as the Structuration of Individual and Opportunity, " Journal of Business Venturing 25(2): 230-237.

Moreno, A. M. and Casillas, J. C. 2008. "Entrepreneurial Orientation and Growth of SMEs." Entrepreneurship Theory and Practice 32(3): 507-528.

Morris, M.H., Avila, R.A. and Allen, J.W. 1993. "Individualism and the Modern Corporation." Journal of Management, 19(3): 595-612.

Morris, M.H., Davis, D.L. and Allen, J.W. 1994. "Fostering Corporate Entrepreneurship." Journal of International Business Studies (First Quarter): 65-89.

Morris, M.H. and Paul, G.W. 1987. "The Relationship between Entrepreneurship and Marketing in Established Firms." Journal of Business Venturing 2: 247-259.

O'Reilly, C. A., Chatman, J. A. and Caldwell, D. F. 1991. "People and Organizational Culture." Academy of Management Journal 34: 487-516.

OECD. 2014. Science, Technology and Industry Outlook. Paris): OECD.

Peterson, R.A. and Berger, G. D. 1971. "Entrepreneurship in Organizations." Administrative Science Quarterly 16(1): 97-106.

Pinchot, G. 1985. Intrapreneuring: Why You Don't Have to Leave the Corporation to Become an Entrepreneur. New York: Harper and Row. 
Podsakoff, P. M., MacKenzie, S. B., Lee, J. and Podsakoff, N. P. 2003. "Common Method Bias in Behavioral Research.” Journal of Applied Psychology 88: 879-903.

Randerson, K. 2016. "Entrepreneurial Orientation." Entrepreneurship \& Regional Development 28(7-8): 580-600.

Rauch, A., Wiklund, J., Frese, M. and Lumpkin, G.T. 2004. "Entrepreneurial Orientation and Business Performance.” In Frontiers of Entrepreneurship Research. Eds. S. A. Zahra, C. G. Brush, P. G. Greene, G. D. Meyer, P. Davidsson, R. T. Harrison, J. Sohl, J. Fiet, M. Lerner, A. Zacharakis and C. Mason. Wellesley, MA: Babson College.

Rauch, A., Wiklund, J., Lumpkin, G.T. and Frese, M. 2009. "Entrepreneurial Orientation and Business Performance.” Entrepreneurship Theory and Practice 33(3): 761-787.

Robbins, S. and Mukerji, D. 1994. Managing Organizations. New Jersey: Prentice-Hall.

Robert, C. and Wasti, S.A. 2002. "Organizational Individualism and Collectivism." Journal of Management 28(4): 544-566.

Sackmann, S. 1992. "Culture and Subcultures.” Administrative Science Quarterly 37, 140 - 161.

Saha, K., Kumar, R., Dutta, S. K. and Dutta, T. 2017. "A Content Adequate Five-Dimensional Entrepreneurial Orientation Scale.” Journal of Business Venturing Insights 8, 41-49.

Sarason, y., Dean, T. and Dillard, J. F. 2006. "Entrepreneurship as the Nexus of Individual and Opportunity." Journal of Business Venturing 21(3): 286-305.

Sathe, V. 1988. "From Surface to Deep Corporate Entrepreneurship." Human Resource Management Review 27(4): 389-411.

Schein, E.H. 1992. Organizational Culture and Leadership. San Francisco: Jossey-Bass.

Schneider, F. 2007. "Shadow Economies and Corruption All over the World." Economics: The Open-Access, Open-Assessment E-Journal 1(5): 1-29.

Schneider, S.C. 1988. "National Vs. Corporate Culture: Implications for Human Resource Management." Human Resource Management 27(2): 231-246.

--- 1989. "Strategy Formulation.” Organization Studies 10(2): 149-168.

Schumpeter, J.A. 1934. The Theory of Economic Development. Cambridge: Harvard University Press.

Shane, S.A. 1992. "Why Do Some Society Invent More Than Others?." Journal of Business Venturing 7: 29-46.

--- 1993. "Cultural Influences on National Rates of Innovation." Journal of Business Venturing 8: 59-73. 
Shane, S.A., Venkataraman, S. and MacMillan, I. 1995. "Cultural Differences in Innovation Championing Strategies." Journal of Management 21(5): 931-952.

Sharma, P. and Chrisman, J.J. 1999. "Toward a Reconciliation of the Definitional Issues in the Field of Corporate Entrepreneurship.” Entrepreneurship Theory and Practice 23(3): 11-17.

Shepherd, D. A., Patzelt, H. and Haynie, J. M. 2010. "Entrepreneurial Spirals." Entrepreneurship Theory and Practice 34(1): 59-82.

Shook, C.L., Ketchen, D.J., Hult, T. and Kacmar, M. 2004. "An Assessment of the Use of Structural Equation Modeling in Strategic Management Research." Strategic Management Journal 25, $397-$ 404.

Sigler, T.H. and Pearson, C.M. 2000. "Creating an Empowering Culture." Journal of Quality Management 5(Spring): $27-57$.

Simsek, Z., Veiga, J. F. and Lubatkin, M. H. 2007. "The Impact of Managerial Environmental Perceptions on Corporate Entrepreneurship.” Journal of Management Studies 44(8): 1398-1424.

Slater, S. and Narver, J.C. 1995. "Market Orientation and the Learning Organization." Journal of Marketing Theory and Practice 59(July): 63- 74.

Spanos, Y. E. and Lioukas, S. 2001. "An Examination into the Causal Logic of Rent Generation." Strategic Management Journal 22(10): 907-934.

Stage, F.K., Carter, H. C. and Nora, A. 2004. "Path Analysis.” The Journal of Educational Research 98(1): 5-12.

Stambaugh, J. E., Martinez, J., Lumpkin, G. T. and Kataria, N. 2017. "How Well Do Eo Measures and Entrepreneurial Behavior Match?." International Entrepreneurship and Management Journal 13(3): 717-737.

Stopford, J.M. and Baden-Fuller, C.W.F. 1994. "Creating Corporate Entrepreneurship." Strategic Management Journal 15: 521-536.

Sutton, S. 1998. "Predicting and Explaining Intentions and Behavior." Journal of Applied Social Psychology 28(15): 1317-1338.

Sykes, H.B. 1986. "The Anatomy of Corporate Venturing Program.” Journal of Business Venturing 1(3): 275-293.

Triandis, H.C., Bontempo, R., Villareal, M.J., Asai, M. and Lucca, N. 1988. "Individualism and Collectivism.” Journal of Personality and Social Psychology 54(2): 323-338.

Triandis, H. C., and Gelfand, M. J. 1998. "Converging Measurement of Horizontal and Vertical Individualism and Collectivism. Journal of Personality and Social Psychology, 74: 118-128.

Venkatraman, N. 1989. "The Concept of Fit in Strategy Research." Academy of Management Review 14(3): 423-444. 
Wales, W. J. 2015. "Entrepreneurial Orientation.” International Small Business Journal 34(1): 3-15.

Wales, W. J., Gupta, V. K. and Mousa, F-T. 2013. "Empirical Research on Entrepreneurial Orientation.” International Small Business Journal 31(4): 357-383.

Wales, W. J., Monsen, E. and McKelvie, A. 2011. "The Organizational Pervasiveness of Entrepreneurial Orientation." Entrepreneurship Theory and Practice 35(5): 895-923.

Wiklund, J. 1998. "Entrepreneurial Orientation as Predictor of Performance and Entrepreneurial Behavior in Small Firms-Longitudinal Evidence." In Frontiers of Entrepreneurship Research. Eds. P. D. Reynolds, W. D. Bygrave, N. M. Carter, S. Menigart, C. M. Mason and P. P. McDougall. Wellesley, MA: Babson College.

Wiklund, J. and Shepherd, D. 2003. "Knowledge-Based Resources, Entrepreneurial Orientation, and the Performance of Small and Medium-Sized Businesses." Strategic Management Journal 24(13): 1307-1314.

--- 2005. "Entrepreneurial Orientation and Small Business Performance." Journal of Business Venturing 20(1): 71-91.

Worldbank 2017. "World Development Indicators Database."

Yilmaz, C., Alpkan, L. and Ergun, E. 2005. "Cultural Determinants of Customer and LearningOriented Value Systems and Their Joint Effects on Firm Performance." Journal of Business Research 58, 1340- 1352.

Zahra, S.A. 1991. "Predictors and Financial Outcomes of Corporate Entrepreneurship." Journal of Business Venturing 6: 259-285.

--- 1993. "Environment, Corporate Entrepreneurship, and Financial Performance." Journal of Business Venturing 8: 319-340.

--- 1996. "Governance, Ownership, and Corporate Entrepreneurship." Academy of Management Journal 39(6): 1713-1735.

Zahra, S.A., Hayton, J.C. and Salvato, C. 2004. "Entrepreneurship in Family Vs. Non-Family Firms." Entrepreneurship Theory and Practice 24: 363-381.

Zahra, S.A., Ireland, D.R., Gutierrez, I. and Hitt, M.A. 2000. "Privatization and Entrepreneurial Transformation." Academy of Management Review 25: 509-524.

Zahra, S.A. and Pearce, J., II , 1990. "Research Evidence on the Miles-Snow Typology." Journal of Management 16(4): 751-768.

Zahra, S.A., Randerson, K. and Fayolle, A. 2013. "Part I: The Evolution and Contributions of Corporate Entrepreneurship Research.”M@n@gement 16(4): 362. 


\section{APPENDIX A}

\section{ENVIRONMENT}

Seven-point, double sided semantic differential-type Likert scales, anchored by descriptive phrases.

\section{Environment - Hostility}

- Very stressful, exacting, hostile, very hard to keep afloat

- A dominating environment, in which my firm's initiatives count for very little against the tremendous competitive, political, or technological forces

- Very risky; a false step can mean my firm's undoing.

\section{Environment - Dynamism}

- Customer requirements and preferences are hard to forecast.

- Competitive actions are difficult to predict.

- The environment is very unpredictable. It is very hard to anticipate the nature or direction of changes.

\section{Environment - Technological Complexity}

- Technologically, a very sophisticated and complex environment

- New technological developments suddenly take place. The speed of technological change is very fast.

- Extremely R\&D oriented industry (e.g., telecommunications, space, drugs)

\section{ENTREPRENEURIAL ORIENTATION}

Seven-point, double sided semantic differential-type Likert scale, anchored by descriptive phrases.

\section{EO - Proactiveness}

- In general, the top managers of my firm have a strong tendency to be ahead of other competitors in introducing novel ideas or products,

- Typically initiates actions which competitors then respond to.

- Is very often the first business to introduce new products/services, operating technologies, administrative techniques, etc.

\section{EO - Competitive Aggressiveness}

- Is very aggressive and intensely competitive

- Typically sacrifices profitability to gain market share.

- Typically adopts a very competitive, "undo-the-competitors" posture.

\section{EO - Innovativeness}

- Very many new lines of products or services have been marketed.

- The top managers favor a strong emphasis on R\&D, technological leadership, and innovations

- Changes in product/service lines have usually been dramatic

\section{EO - Risk Taking}

- Top managers believe that owing to the nature of the environment, bold, wide-ranging acts are necessary to achieve the firm's objectives

- Top managers have a strong proclivity for high-risk projects (with chances of very high rates of return)

- Typically a bold, aggressive posture in order to maximize the probability of exploiting potential opportunities is adopted, when confronted with decision-making situations involving uncertainty. 


\section{EO - Autonomy}

- Certain budgetary procedures are allowed to be bypassed to get funds for an innovation.

- Certain personnel procedures are allowed to be bypassed to get people committed to an innovation.

- It is possible for the people working on an innovation to bypass standard operating procedures to develop the innovation.

\section{MANAGEMENT SUPPORT}

A five item, single-sided, Likert-type scale was utilized.

- People are encouraged to cooperate with workers in other departments about ideas for new projects.

- A worker with a good idea is often given free time to develop that idea.

- Top management is receptive to employee ideas and suggestions.

- Jobs are structured so that work loads are too heavy to spend time on developing new ideas.

- Promotion usually follows the development of new and innovative ideas.

- There are several options for individuals to get financial support for their innovative projects and ideas.

- Supervisors and managers are trained in creativity and innovation techniques.

\section{CORPORATE ENTREPRENEURSHIP}

Single sided, five-point Likert-type scale, ranging from 1 (strongly disagree) to 5 (strongly agree).

\section{CE - Venturing}

- has established or sponsored several new ventures.

- has created new semi- and autonomous units

- has focused on improving the performance of its current business, rather than entering new industries.

\section{CE - Strategic Renewal}

- has changed the organizational structure in significant ways to promote innovation

- has introduced innovative human resource programs to spur creativity and innovation.

- has initiated several programs to improve the productivity of business units.

- has reorganized operations to ensure increased coordination and communication among business units.

- has redefined the industries in which it competes.

CE - Innovation

- has invested heavily (well above industry average) in cutting edge product-oriented R\&D.

- has invested heavily (well above industry average) in cutting edge process-oriented R\&D.

- has copied other companies' process technologies.

- has spent on new product development initiatives.

- has created radically new products for sale in the company's existing markets.

- has been the first company in the industry to introduce new products to the market.

ORGANIZATIONAL CULTURE

Five-point, single-sided, Likert-type scale, ranging from 1 (strongly disagree) to 5 (strongly agree)

\section{OC - Collectivism}


- Group success is more important than individual success.

- Individual needs are put above group needs

- Working with a group is better than working alone.

- Group decisions are more important than individual decisions.

- Values being a team player.

- Group welfare is more important than individual rewards.

- "I" not "We" holds sway

OC - Power Distance

- Managers should make most decisions without consulting with subordinates.

- It is often necessary for a supervisor to emphasize authority and power when dealing with subordinates.

- Managers should be careful not to ask the opinions of subordinates too frequently.

- Subordinates should not disagree with their manager's decisions.

- Managers should not delegate difficult and important tasks to subordinates.

- A manager should avoid socializing with his/her subordinates at the job.

- People at lower levels in organizations have a responsibility to make important decisions for people around them.

- People at lower levels in the organization should not have power in the organization.

\section{CE VALIDATION ITEMS:}

Instead of open questions, to increase the response rate, the informants were offered response scales differing from question to question. The reasonable response intervals had been finalized in the exploratory phase during interviews. At the lowest extreme of each response scale, " 0 " representing no activity was placed for each question. The higher the score, the higher the behavior measured.

\section{Innovativeness:}

- What is the number of new process and production related technologies introduced to the market over the past three years by your firm?

- What is the number of new processes and production related technologies your firm plans to introduce to the market this year?

- What is the number of new products/services your firm plans to introduce to the market this year?

- What is the number of patents/copyrights/utility models/geographic signs acquired over the last three years?

- What is the ratio of your employees who have been trained in entrepreneurship or innovativeness?

- What is the number of new products/services your company has introduced to the market over the past three years?

- What is the ratio of your total $R \& D$ expenditure to your total sales figure?

- What is the number of new customers acquired in the last three years?

\section{Venturing:}

- What is the number of independent and/or semi-independent business units established by your company in the last three years?

- What is the number of new business units established and/or financially supported by your firm in the last three years? 
- What is the number of joint ventures and/or acquisitions realized by your firm in the last three years?

\section{Strategic Renewal:}

- What is the number of new managerial, administrative, and/or human resource programs planned to be initiated this year?

- What is the number of managerial, administrative, and/or human resource programs initiated in the last three years? 